\title{
Effects of M2 Polarization of Microglia on Inflammatory Injury in Cerebral Haemorrhage
}

\author{
X. ZHANG, D. WANG, C. LI, X. JIN AND Y. WU ${ }^{1 *}$ \\ Department of Neurosurgery, ${ }^{1}$ Department of Neurosurgery, Tongde Hospital of Zhejiang Province, No.234 Gucui Road, \\ Hangzhou 310012, China
}

Zang et al.: M2 Polarization of Microglia Injury in Cerebral Haemorrhage

\begin{abstract}
In this study, C57BL/6 mice were used to construct an animal model of cerebral hemorrhage to investigate the effect of M2 polarization of microglia on inflammation injury of cerebral hemorrhage. Regulatory $T$ cells were sorted by immunomagnetic beads, while Western Blot was used to detect the expression of phosphorylation signal transduction and transcription activator 3 , T-signal transduction and transcription activator 3, transforming growth factor- $\beta$ and $\beta$-actin in each group. Enzyme linked immunosorbent assay was used to detect the level of specific antibodies to explore the correlation between $M 2$ polarization of microglia and inflammation injury. Results showed that the expression of an M2 microglia marker chitinase 3 -like 3 and M1-related cytokines, interleukin-6 and tumor necrosis factor $\alpha$ were increased significantly in the regulatory $T$ cell -treated group, along with significantly decreased expressions of an M1 marker and M2-related cytokines, interleukin-10 and transforming growth factor- $\beta$. It was hypothesized that regulatory $T$ cells could regulate $M 2$ polarization of microglia through interleukin-10/signal transduction and transcription activator 3 signaling pathway. In addition, the expression of M2 microglia markers Arg1 and Ym1 increased in the regulatory $T$ cell-treated group, along with decreased expressions of M1 microglia markers, chemokine (C-C motif) ligand 3 and inducible nitric oxide synthase. It was also confirmed that regulatory $T$ cells could induce the $M 2$ polarization of microglia.
\end{abstract}

Key words: Inflammation of cerebral haemorrhage, Treg cells, microglia, M2, enzyme-linked immunosorbent assay

With high morbidity and mortality, spontaneous cerebral haemorrhage accounts for $10-15 \%$ of all cases of stroke ${ }^{[1]}$. Since hypertension and cerebrovascular diseases are high risk factors for cerebral haemorrhage $(\mathrm{CH})$, intracranial surgery is usually accompanied by $\mathrm{CH}^{[2]}$. The disability rate of patients with $\mathrm{CH}$ is always high due to the lack of effective treatment to reduce the neurological damage caused by $\mathrm{CH}$ and secondary brain injury. At present, functional damage to the brain caused by $\mathrm{CH}$ has become a research hotspot.

There are two stages of nerve injury during $\mathrm{CH}$. In the first stage of nerve injury caused by primary hemorrhage, brain tissues are destroyed while peripheral nerve tissues are compressed by blood clots, leading to a primary injury usually shown as physical injury. This stage often occurs before hospitalization and hence the possibility of intervention is low. In the second stage, the local pressure of peripheral nerve tissues is increased by hematoma compression to reduce the effective blood perfusion in the injured region. At the same time, the decomposition products of blood clots exert a cytotoxic effect on adjacent nerve tissues. This stage is mainly featured by a series of chemical and immunological reactions, and is termed as secondary brain injury ${ }^{[3]}$. Therefore, after intracerebral haemorrhage, inflammation plays an important role in brain tissue damage. As small rod-like cells with several withered protrusions, a rough surface, spines and a few branches, microglia are the only type of cells derived from the mesoderm in the nerve system ${ }^{[4]}$ and are less distributed in the central nervous system. In the gray matter, most of microglia are located near the body of neuron cells or around small blood vessels, although microglia can also be seen in the white matter. It has been shown that as a main regulatory mediator affecting the inflammatory response after haemorrhage, microglia play an increasingly prominent role in the immune defense system of the central nervous system ${ }^{[5]}$. 
Microglia have two subtypes, M1 and M2 microglia. M1 polarization of microglia promotes inflammation and kills microorganisms, while M2 polarization of microglia inhibits inflammation and participates in tissue repair and reconstruction ${ }^{[6,7]}$.

In summary, a large number of studies have suggested that different diseases or different stages of the same disease could induce the polarization of microglia leading to different consequences. Therefore, the mechanism underlying the M2 polarization of microglia was studied here using mice as the research object, so as to verify the effects of M2 polarization of microglia on injury induced by $\mathrm{CH}$.

\section{MATERIALS AND METHODS}

SPF grade adult male C57BL/6 mice (100, 6-9 w old, 20-25g) were purchased from the Nanjing Junke Bioengineering, China. The animal disposal and experimental procedures conformed to the National Laboratory Animal standards. All animal experimental protocols were approved by the Ethics Committee of Tongde Hospital of Zhejiang.

\section{Preparation of a CH model:}

C57BL/6 mice were anaesthetized with $4 \mathrm{mg} / \mathrm{kg}$ chloral hydrate (Kelong Chemical Reagents, China) and fixed to a stereotactic apparatus. After iodophor disinfection, a median incision of about $0.5 \mathrm{~cm}$ in length was made. The surface fascia of exposed bone was separated by a pair of tweezers to expose the cranial bone and suture. A small hole was drilled at $0.8 \mathrm{~mm}$ in front of and $2.5 \mathrm{~mm}$ on the right side of the anterior fontanel door to serve as the needling point. An uncoagulated autologous blood sample of $20 \mu 1$ was collected from the tail vein using a $20 \mu 1$ microsampler (Eppendorf, Germany) fixed to the stereotactic instrument (Thermo Scientific, USA).

A needle was inserted slowly into the needle point to a depth of about $3.5 \mathrm{~mm}$, so that the syringe content was injected slowly into the basal ganglia at a rate of $1 \mu \mathrm{l} / \mathrm{min}$. After the injection, the needle was slowly withdrawn using 10-min intervals, with $2 \mathrm{~mm}$ of needle withdrawn in each interval. Bone wax was used to close the hole before the skin was sutured. After the mice gained full consciousness, they were put back into the cages. The mice in the sham operation group were subjected to the same procedure using saline for injection. At $24 \mathrm{~h}$ after operation, regulatory $\mathrm{T}$ cells (Tregs) were sorted by a CD4+CD25+T cell immunomagnetic beads sorting kit (Meitanju, Germany) and then injected into the tail vein of each mouse in a volume of $0.2 \mathrm{ml}$ (about $1 \times 10^{6}$ cells). At the same time, $0.2 \mathrm{ml}$ saline was injected into each mouse in the control group.

\section{Preparation of a spleen single cell suspension:}

Anesthetized mice were fixed on a foam board using the same method described above. After disinfection, the abdominal cavity was opened using a pair of ophthalmic scissors to remove the liver. Then, the spleen was removed using a pair of mosquito forceps and placed on a piece of filter mesh (230 mesh) before the spleen was cut into small pieces and ground filtered through the filter mesh. After homogenization, the cell concentration in the homogenate was adjusted to $>10^{7}$ cells $/ \mathrm{ml}$ and the suspension was stored for future use.

\section{Treg cell sorting by immunomagnetic beads:}

The single cell suspension of mouse spleen was centrifuged in an Eppendorf centrifuge (Germany) for $10 \mathrm{~min}$ at $300 \mathrm{~g}$. The supernatant was discarded and the pellet was re-suspended with $40 \mu 1$ of buffer and then mixed with $10 \mu \mathrm{l}$ of biotin-antibody cocktail. The suspension was incubated in a $4^{\circ}$ refrigerator for $10 \mathrm{~min}$ and then mixed with $30 \mu \mathrm{l}$ of buffer, $10 \mu \mathrm{l}$ of CD25-PE antibody and $20 \mu 1$ of antibiotic micro beads. After mixing, the suspension was incubated at $4^{\circ}$ for 15 min and then sorted using a MACS separator according to the protocol of the manufacturer. The number of lymphocytes used in the magnetic bead sorting was $10^{7}$.

\section{Treg co-culture with microglia using Transwell:}

BV2 cells were placed in the lower chamber of a six-well Transwell plate (BD Biosciences, USA) and stimulated for $6 \mathrm{~h}$ by LPS/IL-4 $(10 \mathrm{ng} / \mathrm{ml})$. After discarding the supernatant, the cells were washed 3 times with preheated PBS and supplemented with a DMEM medium. Then, the Treg cells isolated by immunomagnetic beads were placed in the upper chamber of the Transwell plate while the lower chamber of the Transwell was completely submerged in the medium. After $72 \mathrm{~h}$, the upper chamber of the Transwell plate was removed and the cells were collected for subsequent experiments.

\section{Cell lysis and protein extraction:}

The 6-well Transwell plate was washed 3 times with ice-cold PBS after the culture medium was discarded. RIPA pyrolysate (Biyuntian Biotechnology, China), PMSF and phosphatase inhibitors were mixed in a volume ratio of 100:1:1 and $50 \mu 1$ pyrolysate/well 
were added to the plate, which was then incubated on ice for $5 \mathrm{~min}$ before the pyrolytic cells were scraped off and transferred to a $1.5 \mathrm{ml}$ EP tube. The cells were further lysed using an ultrasound breaker for $50 \mathrm{~s}$. Then, the lysate was centrifuged at $4^{\circ}$ for $15 \mathrm{~min}$ at $12000 \mathrm{~g}$. Ten microlitres of the supernatant was aliquoted to each tube before a bicinchonic acid (BCA) protein assay ( 2 replicates) was carried out to determine protein concentrations.

\section{Determination of protein concentrations using BCA assay:}

Preparation of the protein standard, $20 \mathrm{mg}$ BSA was completely dissolved in $0.8 \mathrm{ml}$ protein standard formulation solution and made into a $25 \mathrm{mg} / \mathrm{ml}$ protein standard mother liquor. Then, the solution was preserved at $-20^{\circ}$ in dark. On the day of experiment, the standard mother liquor was diluted to a $0.5 \mathrm{mg} / \mathrm{ml}$ standard solution with PBS (Doctor De Engineering, China). BCA working solution was prepared by mixing reagent $A$ and reagent $B$ in a ratio of $50: 1(\mathrm{v}: \mathrm{v})$. In a 96-well plate, $0,1,2,4,8,12,16,20 \mu 1$ of standard protein were added followed by the addition of PBS to a final volume of $20 \mu \mathrm{l}$. Their corresponding standard concentrations were $0,0.025,0.05,0.1,0.2,0.3,0.4$ and $0.5 \mathrm{mg} / \mathrm{ml}$, respectively. The plate was incubated at $37^{\circ}$ for $30 \mathrm{~min}$ after adding $200 \mu \mathrm{l} /$ well of the BSA working solution. The absorbance at A562 was determined in a plate reader. The standard curve was drawn and the protein concentration was calculated according to the absorbance value of the samples.

\section{Detection of target protein expressions by Western blotting:}

The preparation of a SDS-PAGE separating gel and a concentrating gel, The molecular weight range of the protein was $15-110 \mathrm{kD}$, and the concentration range of separating gel was $6-12 \%, 11$ and $4 \%$ concentrating gels were selected for protein detection. The formulations of the two gels are shown in Table $1^{[8]}$.

SDS-PAGE gel was made ready by first preparing the separation gel followed by blocking with anhydrous alcohol and keeping at room temperature for 30-40 min. After discarding absolute ethanol, combs were inserted and the gel was incubated overnight at $4^{\circ}$. According to the concentration of the target protein, the volume of the sample was adjusted to ensure the same amount of protein in each well. Three to five prestained markers were added to both sides of each well to facilitate protein localization. Electrophoresis was done at $80 \mathrm{~V}$ constant voltage to allow the bromophenol blue indicator to reach the bottom of the separation gel transfer membrane. Then, the gel was cut according to the range of the target strip. A PVDF film of the same size (Bio-Rad, USA) was prepared, immersed in methanol and transmembrane buffer. Then, the protein bands on the gel were blotted to the PVDF film under $200 \mathrm{~V}$ for $2 \mathrm{~h}$. The PVDF membrane was blocked in $5 \%$ skimmed milk powder (or $5 \%$ BSA) at room temperature for $2 \mathrm{~h}$. The PVDF membrane was rinsed with TBST and incubated overnight with corresponding primary antibodies (Biyun Tian Biological, China) at $4^{\circ}$. After washing 3 times with TBST for 5 min each time, the PVDF membrane was incubated overnight with corresponding secondary antibodies (1:5000) at room temperature for $1 \mathrm{~h}$ and washed with TBST 3 times (5 min each), the PVDF membrane was incubated with ECL reagents (Bio-Rad, USA) and analyzed semi-quantitatively using Imagelab software. The relative gray value of each target protein was calculated using $\beta$-tubulin or $\beta$-actin as reference.

\section{Real-time PCR:}

The sequence of chemokine (C-C motif) ligand 3 (CCL3) primers were $\mathrm{F}$ terminal ATGCAAGTTCAGCTGCCTGC, $\mathrm{R}$ terminal ATGCCGTGGATGAACTGAGG. The sequence of iNOS primers were $F$ terminal AATGGCAACATCAGGTCGGCCATCACT, R terminal GCTGTGTGTCACAGAAGTCTCGAACTC. The sequence of Arg1 primers were $\mathrm{F}$ terminal GAACACGGCAGTGGCTTTAAC, $\mathrm{R}$ terminal TGCTTAGTTCTGTCTGCTTTGC. The sequence of $\mathrm{Yml}$ primers were $\mathrm{F}$ terminal AGAAGGGAGTTTCAAACCTGGT, $\mathrm{R}$ terminal GTCTTGCTCATGTGTGTAAGTGA. The sequence of GAPDH primers were $F$ terminal CACCCACTCCTCCACCTTTG, $\mathrm{R}$ terminal CCACCACCCTGTTGCTGTAG.

\begin{tabular}{|c|c|c|c|}
\hline $\begin{array}{l}11 \% \text { separating } \\
\text { gel }\end{array}$ & $24 \mathrm{ml}$ & $\begin{array}{l}4 \% \text { concentrating } \\
\text { gel }\end{array}$ & $12 \mathrm{ml}$ \\
\hline DW & $8.72 \mathrm{ml}$ & DW & $7.248 \mathrm{ml}$ \\
\hline $\begin{array}{l}3 \mathrm{M} \text { Tris- } \mathrm{HCl} \mathrm{pH} \\
8.8\end{array}$ & $6 \mathrm{ml}$ & $\begin{array}{c}3 \mathrm{M} \text { Tris- } \mathrm{HCl} \mathrm{pH} \\
8.8\end{array}$ & $3 \mathrm{ml}$ \\
\hline $30 \%$ Arc & $8.8 \mathrm{ml}$ & $30 \%$ Arc & $1.56 \mathrm{ml}$ \\
\hline $10 \%$ SDS & $0.48 \mathrm{ml}$ & $10 \%$ SDS & $0.12 \mathrm{ml}$ \\
\hline $10 \%$ APS & $0.24 \mathrm{ml}$ & $10 \%$ APS & $0.06 \mathrm{ml}$ \\
\hline TEMED & $20 \mu \mathrm{l}$ & TEMED & $12 \mu \mathrm{l}$ \\
\hline
\end{tabular}


After intraperitoneal anaesthesia with 5\% chloral hydrate, thoracic cavity of the mice was opened rapidly to expose the heart, the pericardium and surrounding soft tissues were separated bluntly with vascular forceps in order to fully expose the heart. Left-handed tweezers were used to cautiously clamp the heart, while a right-handed indwelling needle was slowly inserted into the left ventricle via the apex of the heart and slowly withdrawn from the core. After puncturing the left atrium, the right auricle was quickly perfused with cold buffer. After perfusion, the skull of each mouse was immediately opened to remove brain tissues, including the olfactory bulb, cerebellum and brain stem. The cerebral hemisphere was then placed in $1 \mathrm{ml}$ of Trizol and homogenized repeatedly using a homogenizer until no obvious cell chunks could be observed. The homogenate was collected into $1.5 \mathrm{~m} \mathrm{EP}$ tubes and mixed with $1 / 5(\mathrm{v} / \mathrm{v})$ chloroform. Then, the homogenate was fully emulsified by $15 \mathrm{~s}$ of vortexing.

After being centrifuged at $12000 \mathrm{~g}$ and $4^{\circ}$ for $15 \mathrm{~min}$, the homogenate in the EP tubes was divided into an upper layer of colourless supernatant (containing RNA), a middle layer of protein and a lower layer of organic phase. The colourless supernatant was carefully transferred to a new RNAse-free (Abbkine, USA) EP tube and mixed with an equal volume of anhydrous ethanol. After through mixing, the mixture was incubated for $10 \mathrm{~min}$ at $4^{\circ}$ and then centrifuged for $10 \mathrm{~min}$ at $12000 \mathrm{~g}$. After the supernatant was carefully discarded, $1 \mathrm{ml}$ of $75 \%$ ethanol was slowly added in the EP tube along the wall. After being fully mixed, the mixture was centrifuged for $5 \mathrm{~min}$ at $4^{\circ}$ and $7500 \mathrm{~g}$. After the pellet was dried at room temperature for $5 \mathrm{~min}$, $25 \mu \mathrm{l}$ DEPC was added to dissolve and precipitate total RNA. After discarding the culture medium, the cells were washed twice with precooled PBS and lysed with Trizol according to the protocol of the manufacturer. Subsequently, total RNA was extracted from the lysate using the same procedure as described above.

Reverse transcription of RNA into cDNA was achieved by preparing a $20 \mu \mathrm{l}$ system for reverse transcription according to Table 2A. Reverse transcription program in a polymerase chain reaction instrument (Bio-Rad, USA), $42^{\circ}$ for $30 \mathrm{~min}, 4^{\circ}$ for $10 \mathrm{~min}$, cooled on ice. The obtained cDNA was directly used for subsequent PCR or stored at $-80^{\circ}$ for later use. The real-time PCR system used is shown in Table $2 \mathrm{~B}$. The procedure of quantitative PCR was pre-denaturation at $95^{\circ}$ for $30 \mathrm{~s}$, denaturation at $95^{\circ}$ for $5 \mathrm{sec}$ and 40 cycles of denaturation and annealing at $60^{\circ}$ for $30 \mathrm{~s}$.
TABLE 2: REACTION SYSTEMS

\begin{tabular}{|c|c|c|}
\hline & Component & Volume \\
\hline & Total RNA & $2 \mu g$ \\
\hline & $5 \times$ first-strand Buffer & $4 \mu \mathrm{l}$ \\
\hline & M-Mu LV reverse transcriptase $(200 \mathrm{U} / \mu \mathrm{l})$ & $1 \mu \mathrm{l}$ \\
\hline \multirow[t]{6}{*}{ A } & Oligo dT primer $(50 \mu \mathrm{M})$ & $1 \mu \mathrm{l}$ \\
\hline & dNTP mixture (10 mM each) & $1 \mu \mathrm{l}$ \\
\hline & RNase inhibitor $(40 \mathrm{U} / \mu \mathrm{l})$ & $1 \mu \mathrm{l}$ \\
\hline & RNase-free $\mathrm{dH}_{2} \mathrm{O}$ & up to $20 \mu \mathrm{l}$ \\
\hline & $2 \times$ Super SYBR premixture & $5 \mu \mathrm{l}$ \\
\hline & PCR forward primer $(10 \mu \mathrm{M})$ & $0.2 \mu \mathrm{l}$ \\
\hline \multirow[t]{3}{*}{ B } & PCR reverse primer $(10 \mu \mathrm{M})$ & $0.2 \mu \mathrm{l}$ \\
\hline & CDNA & $1 \mu \mathrm{l}$ \\
\hline & RNase-free $\mathrm{dH}_{2} \mathrm{O}$ & up to $10 \mu \mathrm{l}$ \\
\hline
\end{tabular}

A: Reverse transcription; B: real-time PCR

\section{Enzyme-linked immunosorbent assay:}

Brain tissue was homogenized in a homogenizer and then transferred into centrifugal tubes, and centrifuged for $10 \mathrm{~min}$ at $12000 \mathrm{~g}$. The blank control well, standard well and sample well to be tested were set respectively. The blank control well was only added with chromogenic agent $\mathrm{A}$, chromogenic agent $\mathrm{B}$ and the termination solution. The standard well was added with $50 \mu 1$ of standard samples in order. The plate was sealed and mixed gently, incubated at $37^{\circ}$ for $60 \mathrm{~min}$. Then, the plate was washed before $200 \mu \mathrm{l} /$ well of detergents were added and the process was repeated 5 times. After the plate was washed again, $100 \mu \mathrm{l} /$ well of diluted antibodies $(1: 100)$ were added into the 96-well plate and incubated at $37^{\circ}$ for $60 \mathrm{~min}$. After washing 5 times, $100 \mu \mathrm{l} /$ well HRP-coupled secondary antibodies (1:1000) were added into the standard wells and the sample wells. After the plate was mixed gently, it was incubated at $37^{\circ}$ for $60 \mathrm{~min}$. After washing 5 times, $50 \mu \mathrm{l} /$ well of colour developers A and B were added in order. After the plate was mixed gently, it was incubated at $37^{\circ}$ for $10 \mathrm{~min}$ away from light. Then, $100 \mu 1 /$ well of TMB substrate was added into to the plate, which was incubated at $37^{\circ}$ for $10 \mathrm{~min}$. Finally, $100 \mu \mathrm{l} /$ well of termination solution was added to the plate and the OD value of each well was determined at a $450 \mathrm{~nm}$ wavelength using an Eppendorf instrument. The concentration of cell supernatant in each group was calculated according to its OD value. Each experiment was repeated at least 3 times.

\section{Statistical analysis:}

SPSS17.0 statistical software was used to test the normality and homogeneity of variance. The data were expressed as mean $\pm \mathrm{SD}$. Independent sample t-test was used to compare the 2 groups. The test level was $\alpha=0.05$. 


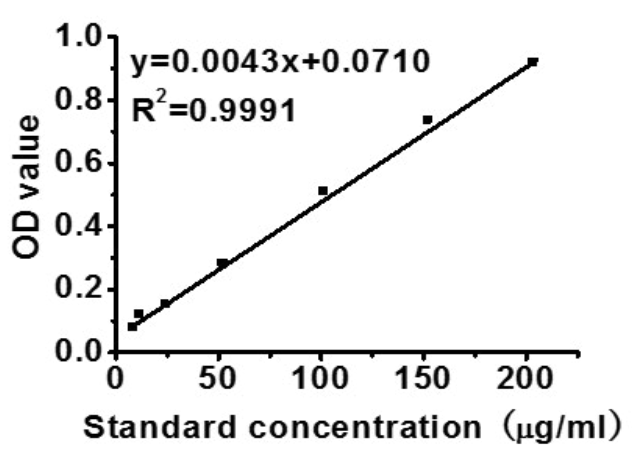

A
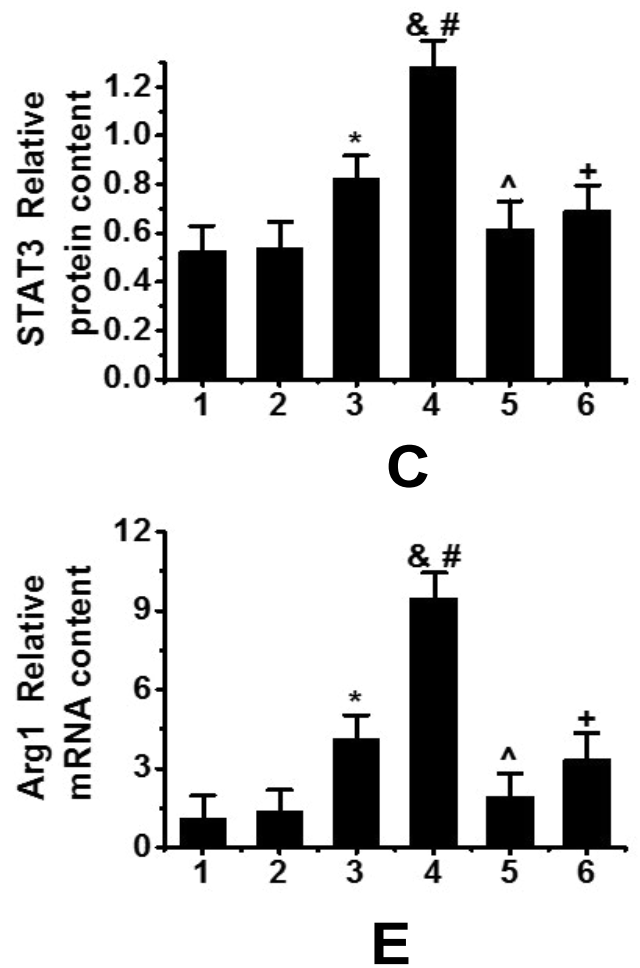

\section{$\begin{array}{llllll}1 & 2 & 3 & 4 & 5 & 6\end{array}$}

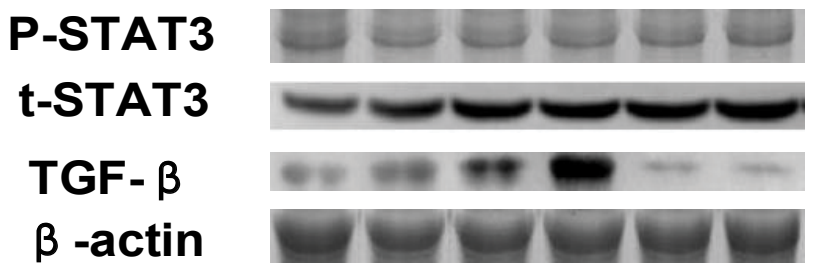

B
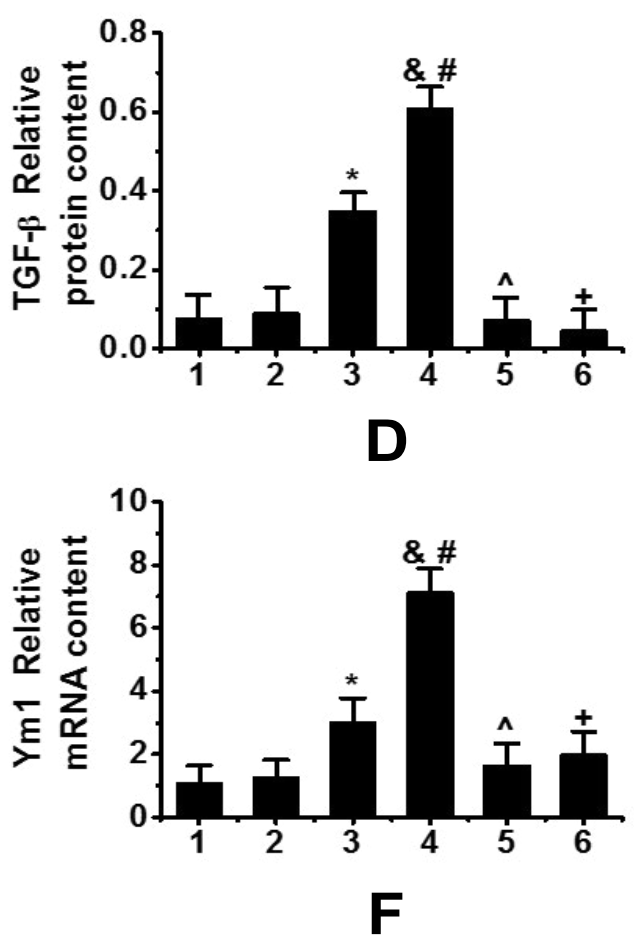

Fig. 1: Tregs regulated microglial polarization through IL-10/STAT3 signaling pathway

1. BV2 culture group, 2. BV2 and Tregs co-culture group, 3. LPS/IL-4-stimulated BV2 group, 4. LPS/IL-4 pre-stimulated coculture group of BV2 and Tregs, 5. LPS/IL-4-stimulated BV2 culture group treated with IL-10 antibody, 6. LPS/IL-4-stimulated co-culture group of BV2 and Tregs treated with IL-10 antibody. A. Standard curve of BCA assay, B. Western blot detection of t-STAT3, p-STAT3, p-STAT3, TGF- $\beta$ and $\beta$-actin, C. semi-quantitative analysis of p-STAT3/t-STAT3, D. semi-quantitative analysis of TGF- $\beta$, E. relative expression of Arglgl mRNA, F. relative expression of $\mathrm{YmL} \mathbf{m R N A}$. $* \mathbf{P}<0.05$, compared with BV2 culture group; $"$ p $<0.05$ compared with BV2 and BV2/Tregs co-culture groups, ${ }^{\&}$ p $<0.05$, compared with LPS/IL-4-stimulated BV2 group, ${ }^{\wedge} p<0.05$, compared with LPS/IL-4-stimulated BV2 group, $+p<0.05$, compared with LPS/LL-4 pre-stimulated BV2 and Tregs coculture group

\section{RESULTS AND DISCUSSION}

As shown in fig. 1, R2 was 0.9991 in the standard curve of protein concentrations determined by the BCA assay (fig. 1A). Western blots results showed the trend of phosphorylation signal transduction and transcription activator 3 (p-STAT3), t-signal transduction and transcription activator 3 (t-STAT3), transforming growth factor- $\beta$ (TGF- $\beta)$ and $\beta$-actin protein expressions in the peri hematoma tissues of 6 groups after intracerebral hemorrhage (fig. 1B). As can be seen, the expression of STAT3 in the co-culture group increased after BV2 stimulation and the expression of STAT3 in the coculture group pre-stimulated by lipopolysaccharide (LPS)/interleukin-4 (IL-4) was significantly higher than that in the LPS/IL-4 stimulated BV2 group (fig. 1C). The expression of TGF- $\beta$ in the co-culture group prestimulated by LPS/IL-4 was also significantly higher than that in other groups (fig. 1D). 

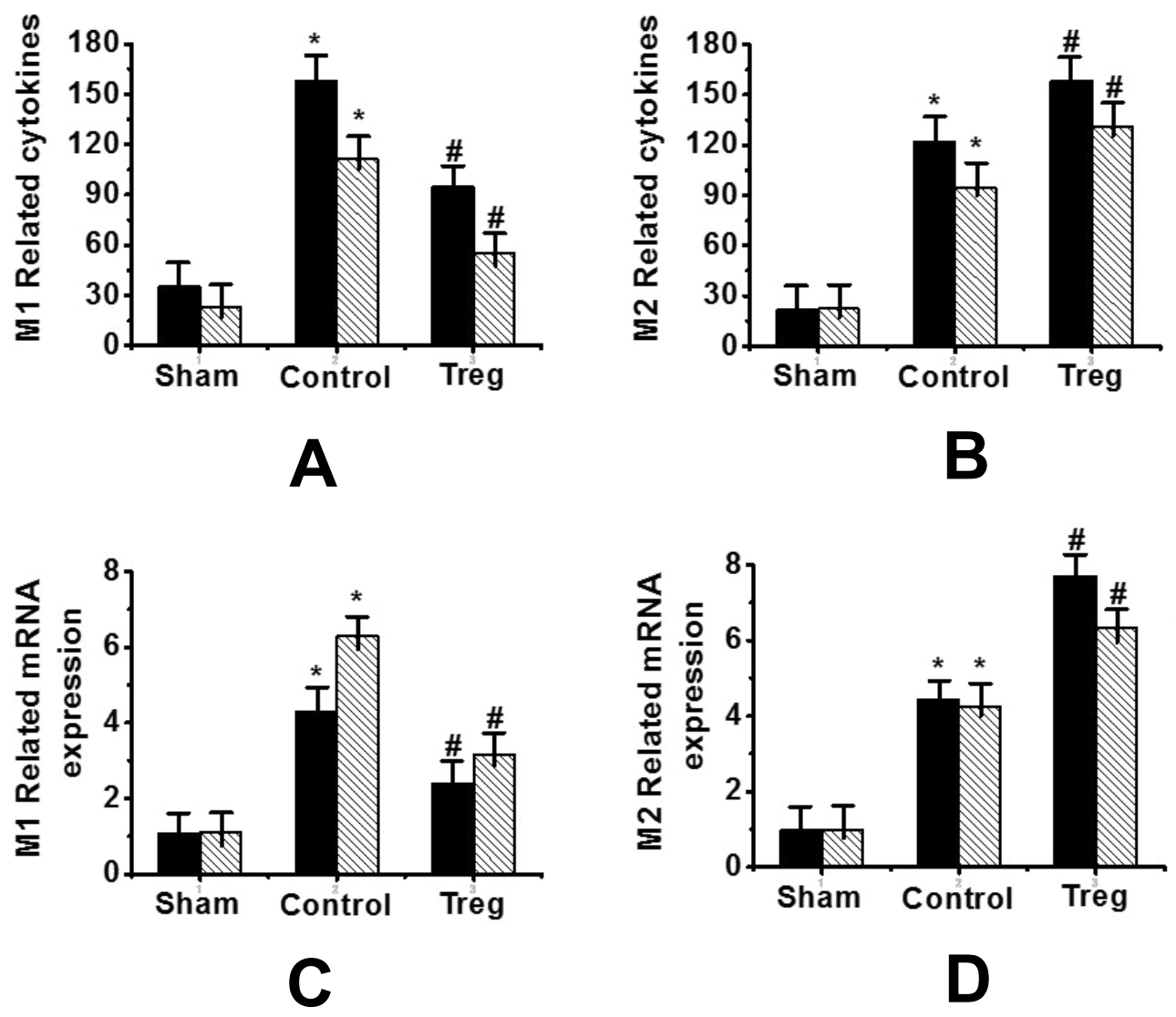

Fig. 2: Tregs induced the M2 polarization of microglia/macrophages in brain tissues around hematoma A. M1-related markers IL-6 and TNF- $\alpha$ detected by ELISA, ( $\square$ ) IL-6, ( $\square$ ) TNF- $\alpha$; B. M2-related markers IL-10 and TGF- $\beta$ detected by ELISA, (घ) IL-10 ( $\square$ ) TGF- $\beta$; C. M1-related markers CCL3 and iNOS detected by PCR, (ø) CCL3, ( $\square$ ) iNOs; D. M2-related markers Arg1 and Ym1 detected by PCR in peri hematoma tissues, (घ) Arg1, ( $\square$ ) Ym1. *P<0.05 compared to sham-operated group, ${ }^{\#} \mathbf{p}<0.05$ compared to control group $(n=3)$.

Meanwhile, the expression of M2-related genes, Arg1 and Ym1, as well as TGF- $\beta$ was increased in the BV2 group stimulated by LPS/IL-4 and in the co-culture group pre-stimulated by LPS/IL-4, but their expression in the co-culture group stimulated by LPS/IL-4 was significantly higher than that in the BV2 group stimulated by LPS/IL-4 (figs. 1E and 1F). Tregs could induce the M2 polarization of microglia by increasing the expression of phosphorylated STAT3. In order to further confirm that Treg cells activated STAT3 via the IL-10 pathway to induce the M2 polarization of microglia, an IL-10 antibody was used to neutralize IL10. It was found that the inhibition of IL-10 expression significantly decreased the expression of STAT3 in microglia. When IL-10 was neutralized, the expression of microglia-related genes (Arg1 and $\mathrm{Ym} 1$ ) in M2 microglia also decreased significantly and the effect of Tregs was reversed. These results suggested that Tregs could regulate the $\mathrm{M} 2$ polarization of microglia through IL-10/STAT3 signaling pathway.
Fig. 2 showed the detection of inflammatory factors in the surrounding tissues of hematoma by ELISA. IL- 6 and TNF- $\alpha$ were used as M1 markers, while IL10 and TGF- $\beta$ were used as M2 markers, respectively. Compared to the control group, the levels of IL-10 and TGF- $\beta$ in the Tregs treatment group increased significantly, along with decreased levels of IL-6 and TNF-a (figs. 2A and B). In addition, the expression of M2 microglia markers Arg1 and Ym1 in the Tregs treatment group increased, along with decreased expressions of M1 microglia markers CCL 3 and iNOS (figs. 2C and D).

Fig. 3 showed that it was difficult to distinguish microglia from macrophages by cell surface markers in animal experiments, so it was difficult to determine whether Tregs cells induce the M2 polarization of microglia or peripheral infiltrating macrophages. At the same time, because of the complexity of cells in brain tissues, many factors may affect each other. Therefore, a cell experiment was designed to analyse the effects of Tregs on microglia by the co-culture of microglia BV2 

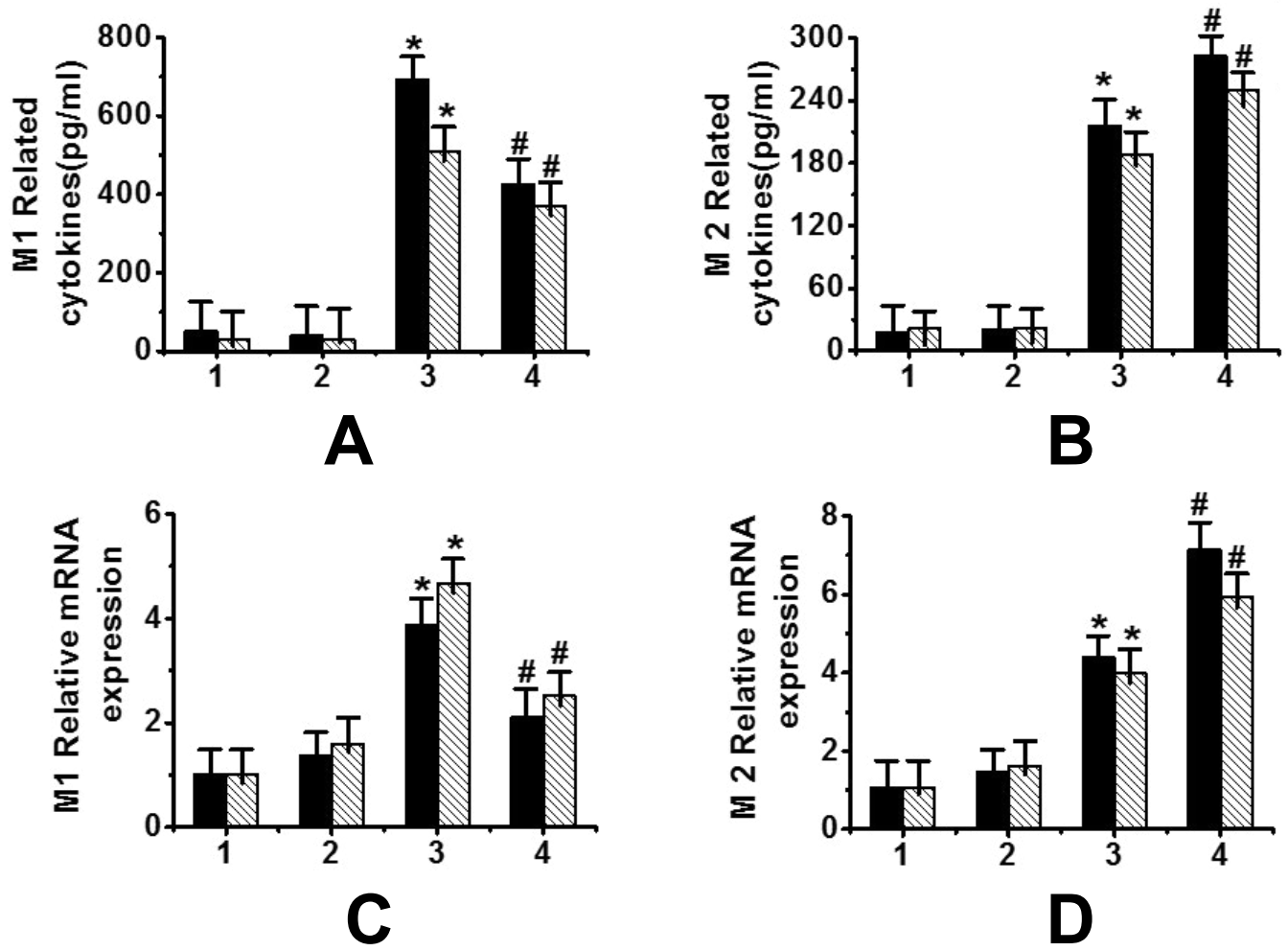

Fig. 3: Tregs induced M2 polarization in LPS/IL4-activated BV2 microglia

1. BV2 group, 2. BV2 and Tregs co-culture group, 3. LPS/IL-4-stimulated BV2 group, 4. LPS/IL-4 pre-stimulated BV2 and Tregs co-culture group, A. M1-related cytokines IL-6 and TNF- $\alpha$ detected by ELISA, ( $\square$ ) IL-6, ( $\square$ ) TNF- $\alpha$, B. M2-related cytokines IL-10 and TGF- $\beta$ detected by ELISA, ( $\square)$ IL-10 ( $\square$ ) TGF- $\beta$, C. M1-related cytokines CCL3 and iNOS detected by PCR, ( $\square)$ CCL3, ( $\square)$

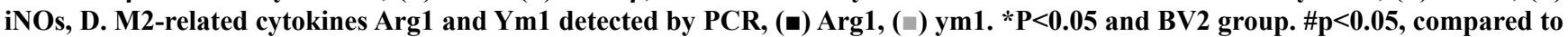
LPS/IL-4-stimulated BV2 group

cells and Tregs. After $72 \mathrm{~h}$ of co-culture of Tregs with activated microglia, the expression of M1-related genes, IL-6, TNF- $\alpha$ (fig. 3A), CCL3 and iNOS (fig. 4), was significantly increased $(\mathrm{P}<0.05)$, while the expression of M2-related genes, i.e., IL-10, TGF- $\beta$ (fig. 3B), Arg1 and Ym1 (fig. 3D), was significantly decreased $(\mathrm{p}<0.05)$. A cell culture model further confirmed that Tregs could induce the M2 polarization of microglia.

Treg cells play an immunoregulatory role by secreting IL-10 $0^{[9]}$, a multipotent immunoregulatory factor playing an important role in inflammatory and immune responses. IL-10 plays its regulatory role by activating STAT3, which in turn could induce M2 polarization of microglia ${ }^{[10]}$. In this study, it can be concluded that the pre-stimulation of a co-culture of BV2 and Tregs with LPS/IL-4 increases the protein expression of STAT3. In addition, the co-culture of BV2 and Tregs prestimulated with LPS/IL-4 showed a significantly higher expression level of STAT3 than LPS/IL-4-stimulated BV2 cells alone. Furthermore, the co-culture of BV2 and Tregs pre-stimulated with LPS/IL-4 showed a significantly higher expression level of TGF-beta than other groups.
The M2 polarization of microglia is induced by the activation of STAT3 in Tregs treated by IL-10. When an IL-10 antibody was used to neutralize IL-10, it was found that the inhibition of IL-10 expression significantly decreased the expression of STAT3 in microglia. When IL-10 was neutralized, the expression of microgliarelated genes (Arg1 and $\mathrm{Ym} 1$ ) in M2 microglia also decreased significantly, and the effect of Tregs was reversed. Therefore, due to the high expression of IL10 in the microenvironment, Treg cells can induce the M2 polarization of microglia through IL-10/STAT3 signalling pathway. As the constituent cells of brain tissues, microglia are generally considered to affect the special morphology of macrophages in the brain tissues $^{[11]}$. Microglia and macrophages are both derived from primordial bone marrow progenitor cells, so it is impossible to distinguish microglia from macrophages by immunohistochemistry assays. Therefore, microglia/ macrophages have been used together in many studies to elucidate the role of microglia ${ }^{[12]}$. After brain injury, activated microglia express 2 subtypes of markers at the same time and the levels of these markers are in dynamic change to affect the prognosis of brain 
injury ${ }^{[13,14]}$. Microglia undergoing M1 polarization are the main source of TNF- $\alpha$ and IL- $\beta$. In the early stage of $\mathrm{CH}$, high levels of inflammatory response mediated by M1 microglia can exert a protective effect ${ }^{[15]}$. In the middle and late stages of haemorrhage, the levels of M2 microglia/macrophages are increased to elevate the levels of protective antiinflammatory cytokines, such as IL-10 and TGF- $\beta$ and to reduce the degree of inflammation. Through enhanced phagocytosis, necrotic tissues and various inflammatory factors are removed to promote tissue repair ${ }^{[16]}$. The results of this study showed that Treg cells can alleviate the inflammation damage to brain tissues caused by cerebral hemorrhage. It can also be inferred that Treg cells can alleviate neuroinflammation by directly inducing the M2 polarization of microglia after cerebral hemorrhage.

In conclusion, the results of this study showed that Tregs can regulate the M2 polarization of microglia through IL-10/STAT3 signalling pathway. The expression of markers for M2 microglia, such as Arg1 and Ym1, increased in the Tregs treatment group, along with decreased expressions of markers for M1 microglia, such as CCL3 and iNOS. In addition, this study confirmed that Tregs can induce the M2 polarization of microglia.

\section{REFERENCES}

1. Muffat J, Li Y, Yuan B. Efficient derivation of microglialike cells from human pluripotent stem cells. Nat Med 2016;22(11):1358.

2. Kaniowska D, Wenk K, Emmrich F. Modulation of microglia responses via mesenchymal stromal cells derived-extracellular vesicles. J Extracell Vesicles 2018;7:176.

3. Jaimes Y, Naaldijk Y, Wenk K. Mesenchymal stem cellderived microvesicles modulate lipopolysaccharides-induced inflammatory responses to microglia cells. Stem Cells 2017;35(3):812-23

4. Gilbert D F, Stebbing M J, Kuenzel K. Store-operated Ca2+ entry (SOCE) and purinergic receptor-mediated $\mathrm{Ca} 2+$ homeostasis in murine bv2 microglia cells: early cellular responses to ATP-mediated microglia activation. Front Mol Neurosci 2016;9:111.

5. Russo I, Berti G, Plotegher N. Erratum to: Leucine-rich repeat kinase 2 positively regulates inflammation and downregulates NF- $\kappa \mathrm{B}$ p50 signaling in cultured microglia cells. J Neuroinflammation 2016;13(1):70.
6. Han Q, Yuan Q, Meng X. 6-Shogaol attenuates LPS-induced inflammation in BV2 microglia cells by activating PPAR- $\gamma$. Oncotarget 2017;8(26):42001.

7. Izraely S, Ben-Menachem S, Sagi-Assif O. The metastatic microenvironment: Melanoma-microglia cross-talk promotes the malignant phenotype of melanoma cells. Int $\mathrm{J}$ Cancer 2019;144(4):802-17.

8. Li H, Zhang $\mathrm{X}$, Chen $\mathrm{M}$. Dexmedetomidine inhibits inflammation in microglia cells under stimulation of LPS and ATP by c-Fos/NLRP3/caspase-1 cascades. EXCLI J 2018;7:302.

9. Luo Q, Yan X, Bobrovskaya L. Anti-neuroinflammatory effects of grossamide from hemp seed via suppression of TLR4-mediated NF- $\kappa \mathrm{B}$ signaling pathways in lipopolysaccharidestimulated BV2 microglia cells. Mol Cell Biochem 2017;428 (1-2):129-37.

10. Hughes LD, Ghosh S, Rothlin CV. Cenabis Bene: Treg Cells Invite Macrophages to Dine. Immunity 2018;49(4):579-582.

11. Edwards JP, Hand TW, Morais da Fonseca D. The GARP/ Latent TGF- $\beta 1$ complex on Treg cells modulates the induction of peripherally derived Treg cells during oral tolerance. Eur J Immunol 2016;46(6):1480-89.

12. Rey C, Nadjar A, Buaud B. Resolvin D1 and E1 promote resolution of inflammation in microglial cells in vitro. Brain Behav Immun 2016;55:249-59.

13. Bennett M L, Bennett F C, Liddelow S A. New tools for studying microglia in the mouse and human CNS. Proc Natl Acad Sci 2016;113(12):E1738-E1746.

14. Jaimes Y, Naaldijk Y, Wenk K. Mesenchymal stem cellderived microvesicles modulate lipopolysaccharides-induced inflammatory responses to microglia cells. Stem Cells 2017;35(3):812-23.

15. Xu H, Rajsombath MM, Weikop P. Enriched environment enhances $\beta$-adrenergic signaling to prevent microglia inflammation by amyloid- $\beta$. EMBO Mol Med 2018;10(9):e8931.

16. Yuan L, Liu S, Bai X. Oxytocin inhibits lipopolysaccharideinduced inflammation in microglial cells and attenuates microglial activation in lipopolysaccharide-treated mice. $\mathrm{J}$ Neuroinflammation 2016;13(1):77.

This is an open access article distributed under the terms of the Creative Commons Attribution-NonCommercial-ShareAlike 3.0 License, which allows others to remix, tweak, and build upon the work non-commercially, as long as the author is credited and the new creations are licensed under the identical terms

This article was originally published in a special issue: Special issue on "Trends in therapeutic Management of Various Conditions" Indian J Pharm Sci 2020:82(3) spl issue 6;xx-xx 